\title{
Resíduos agroflorestais utilizados na germinação e desenvolvimento de mudas de angelim-doce
}

\author{
João Ricardo Avelino Leão ${ }^{1 *}$ \\ Ary Vieira de Paiva ${ }^{2}$ \\ João Paulo da Cunha Lima ${ }^{3}$ \\ ${ }^{1}$ PPG em Ciência, Inovação e Tecnologia para Amazônia, UFAC/EMBRAPA \\ ${ }^{2}$ Centro de Ciências Biológicas e da Natureza \\ Universidade Federal do Acre \\ BR 364, km 4, Distrito Industrial, CEP 69915-900, Rio Branco - AC, Brasil \\ * Autor para correspondência \\ ricardo.leao@ac.gov.br
}

Submetido em 07/05/2012

Aceito para publicação em 09/11/2012

\section{Resumo}

Este artigo objetivou definir o tipo de substrato agroflorestal ideal e a profundidade adequada de semeadura de angelim-doce, gerando informações sobre o desenvolvimento das mudas e sobre substratos de baixo custo e de fácil obtenção. Realizou-se um experimento em casa de vegetação, em delineamento inteiramente casualizado com tratamentos distribuídos em esquema fatorial (5x3), com os fatores substratos agroflorestais e profundidades sendo replicados sete vezes com uma semente em cada recipiente. Foram analisados os seguintes parâmetros: porcentagem de germinação, índice de velocidade de germinação, peso seco total, número de folhas, altura e diâmetro do coleto das mudas e índice de qualidade de mudas de Dickson. Os resultados mostraram que o substrato mais indicado para a germinação e desenvolvimento desta espécie nativa foi o que continha casca de castanha-do-brasil, casca de amendoim ou semente de açaí e a profundidade ideal para a semeadura e condução das mudas foi na superfície.

Palavras-chave: Análise de sementes; Andira inermis inermis; Espécie florestal nativa; Sementes florestais

\section{Abstract}

Agroforestry wastes used for germination and development of sweet angelim seedlings. This paper aimed to define the ideal type of agroforestry substrate and the adequate depth of sweet angelim sowing, providing information on the development of seedlings, as well as on low-cost substrates which are easy to be obtained. An experiment in a greenhouse was carried out, in a completely randomized design with treatments distributed in a factorial scheme $(5 \times 3)$, with the factors agroforestry substrates and depths being replicated seven times with a seed in each container. The following parameters were analyzed: germination percentage, germination speed index, total dry weight, number of leaves, seedlings height and coll diameter, and Dickson's seedling quality index. The results showed that the most suitable substrate for germination and development of this native species was that containing Brazil nut shell, peanut hull, or açai seed, and the ideal depth for sowing and managing seedlings was on the surface.

Key words: Andira inermis inermis; Forest seeds; Native forest species; Seed analysis 


\section{Introdução}

Atividades agroflorestais geram resíduos, em larga escala, que estão sendo utilizados ano a ano na formulação de substratos para a produção de mudas em viveiros comerciais e institucionais na Amazônia (BEZERRA et al., 2009; PEREIRA, 2009; BRITO, 2010; LEÃO; PAIVA, 2010). Segundo Ferreira et al. (2009), o conhecimento sobre técnicas de cultivo e de produção de mudas de espécies nativas utilizando-se substratos compostos por resíduos agroflorestais ainda é incipiente. Dessa forma, grande quantidade destes resíduos é disposta e armazenada irregularmente, tornando-se poluidora. Uma das formas de se trabalhar esta questão é desenvolver substratos capazes de melhorar o processo produtivo e, ao mesmo tempo, cooperar com a conservação do meio ambiente.

Resíduos agroflorestais podem se tornar insumos importantes na produção de mudas de qualidade. Logo, contribuem para o sucesso durante o estabelecimento de essências florestais em campo. A utilização de resíduos na formulação de substratos contribui tanto para a redução do impacto ao meio ambiente como também para a redução de custo, pois esses materiais estão disponíveis em todas as regiões (BEZERRA et al., 2009).

Segundo Leão (2011), resíduo agroflorestal pode ser definido como todo material orgânico proveniente de atividades florestais ou agropecuárias, como casca de castanha-do-brasil, casca de amendoim, palha de arroz, semente de açaí, casca de coco, pó de serra com destinação ainda incerta, tornando-se um potencial poluidor da degradação do meio ambiente.

Vários fatores afetam a qualidade das mudas durante a produção, aspectos intrínsecos e extrínsecos relacionados, por exemplo, ao substrato e a profundidade, podem influenciar no processo de germinação das sementes e no posterior estabelecimento da plântula (VASQUEZ-YANES; OROSCO-SEGOVIA, 1996).

O substrato tem como principal função dar sustentação às sementes, tanto do ponto de vista físico como químico, sendo constituído pela fração física, química e biológica (NEGREIROS et al., 2004). Para
Gomes e Silva (2004), a escolha do substrato deve ser feita levando em consideração os aspectos econômicos, pois além de propiciar adequado crescimento à planta, o material utilizado na composição do substrato deve ser abundante na região e ter baixo custo. Um bom substrato deve apresentar boa capacidade de retenção de nutrientes, umidade, boa aeração, baixa resistência à penetração das raízes e boa resistência à perda de estrutura (SILVA JÚNIOR; VISCONTI, 1991).

A profundidade de semeadura deve ser um pouco maior que o diâmetro da semente. A profundidade de semeadura é específica para cada espécie e quando adequada, propicia germinação e emergência de plântulas uniformes (DEICHMANN, 1967; SOUSA et al., 2007). Para Tillmann et al. (1994), profundidades de semeaduras excessivas podem impedir que a plântula ainda frágil possa emergir à superfície do solo. Contudo, se reduzidas, predispõem as sementes a qualquer variação ambiental, como excesso ou déficit hídrico ou térmico, as quais podem dar origem a plântulas pequenas e fracas. A profundidade ideal de semeadura é aquela que garante uma germinação homogênea das sementes, rápida emergência das plântulas e produção de mudas vigorosas (JELLER; PEREZ, 1997).

A espécie nativa Andira inermis (W.Wright) DC. subsp. inermis (Fabaceae - Papilionoidea) tem hábito arbóreo e é nativa do estado do Acre (SILVEIRA; DALY, 2009). O gênero Andira compreende o grupo de vegetais popularmente conhecidos por angelins e é representado por mais de 30 espécies (PENNINGTON; LIMA, 1995) distribuídas pela América Tropical e uma espécie na África (PENNINGTON; LIMA, 1995), sendo que a maioria é originária do Brasil.

Diante do exposto, o presente estudo objetivou avaliar a influência dos diferentes tipos de substratos, originados a partir de resíduos agroflorestais, na germinação e desenvolvimento de mudas de angelimdoce e determinar a profundidade mais adequada de semeadura. E com isto gerar um protocolo de produção de mudas desta espécie nativa. 


\section{Material e Métodos}

\section{Localização da área de estudo}

O experimento foi conduzido no interior da casa de vegetação localizada nas dependências do viveiro de mudas e no laboratório de análise de sementes florestais do Parque Zoobotânico da Universidade Federal do Acre (PZ/UFAC), localizada na BR-364, km 4, Distrito Industrial, Rio Branco, Acre nas coordenadas geográficas de $09^{\circ} 57,417^{\prime} \mathrm{S}$ de latitude e $67^{\circ} 52,441^{\prime} \mathrm{W}$ de longitude.

Os frutos de angelim-doce foram coletados em três árvores matrizes localizadas no PZ/UFAC, que abrange uma área de aproximadamente 100ha e situa-se na região leste do Estado do Acre, dentro do campus da UFAC.
A coleta dos frutos ocorreu nos meses de janeiro e fevereiro de 2009 de forma manual, no chão, próximo às árvores matrizes. Posteriormente, foram acondicionados em sacos plásticos e mantidos por uma semana em temperatura ambiente, nas dependências do viveiro, até a etapa do beneficiamento, secagem natural e armazenamento em câmara fria até a instalação do experimento, período este que durou um mês.

\section{Coleta e preparação dos substratos}

Os resíduos agroflorestais (Figura 1) utilizados no ensaio foram coletados nas dependências do viveiro de mudas da UFAC. Somente a casca de castanhado-brasil e casca de amendoim foram triturados para

FIGURA 1: Resíduos agroflorestais aproveitados na produção de mudas de angelim-doce, viveiro de mudas do Parque Zoobotânico/UFAC, Rio Branco, Acre. S1 - casca de castanha-do-brasil; S2 - casca de amendoim; S3 - palha de arroz e S4 - semente de açaí.




redução e melhor agregação das partículas na Unidade de Tecnologia de Alimentos (UTAL/UFAC). A palha de arroz e semente de açaí foram usadas em seu estado natural, ou seja, sem desagregação de partículas.

A terra de subsolo (horizonte B) utilizada no experimento foi coletada no viveiro e a sua preparação ocorreu de acordo com a análise de fertilidade de solo, realizada pelo Laboratório de Fertilidade de Solo da UFAC. Após esta fase ocorreu a composição dos substratos utilizados na pesquisa na proporção de $70 \%$ de resíduo agroflorestal e 30\% de terra de subsolo, e a testemunha com $100 \%$ de terra de subsolo para controle do experimento (Tabela 1).

TABELA 1: Composição dos substratos utilizados no experimento com sementes de Andira inermis subsp. inermis, Rio Branco, Acre, 2009.

\begin{tabular}{llc}
\hline & Substratos & $\begin{array}{c}\text { Proporção } \\
(\%)\end{array}$ \\
\hline Substrato (S1) & $\begin{array}{l}\text { Casca de castanha-do-brasil } \\
\text { triturada + terra de subsolo }\end{array}$ & $70+30$ \\
Substrato (S2) & $\begin{array}{l}\text { Casca de amendoim } \\
\text { triturada + terra de subsolo }\end{array}$ & $70+30$ \\
Substrato (S3) & $\begin{array}{l}\text { Palha de arroz + terra de } \\
\text { subsolo }\end{array}$ & $70+30$ \\
Substrato (S4) & $\begin{array}{l}\text { Semente de açaí + terra de } \\
\text { subsolo }\end{array}$ & $70+30$ \\
Substrato (S5) & $\begin{array}{l}\text { Terra de subsolo } \\
\text { (testemunha) }\end{array}$ \\
\hline
\end{tabular}

\section{Instalação e condução do experimento}

O experimento foi instalado e conduzido sobre bancadas de madeira em condições ambientes $\left(30,76^{\circ} \mathrm{C}\right.$ e $73,43 \%$ UR) no interior da casa de vegetação. A determinação da profundidade foi realizada de acordo com a biometria das sementes, pelo qual se padronizou a profundidade inicial como $0,0 \mathrm{~cm}(\mathrm{P} 1), 6,0 \mathrm{~cm}(\mathrm{P} 2)$, $12,0 \mathrm{~cm}(\mathrm{P} 3)$.

Em seguida as sementes selecionadas foram dispostas em sacos plásticos de polietileno preto com dimensões de 10 x $24 \mathrm{~cm}$, em que cada saco representava uma parcela experimental, com uma semente em cada, contendo os diferentes substratos. Os substratos foram irrigados diariamente com regador manual.
A semeadura foi realizada dia 21/04/09 e somente dia 08/07/09 foi observado o início da germinação das sementes, o período entre a semeadura e a primeira germinação foi de aproximadamente 70 dias. As observações decorreram durante 180 dias após a primeira emergência. $\mathrm{O}$ estudo foi finalizado quando se constatou a estagnação da germinação. Este longo período de análise justifica-se devido à carência de estudos acerca da propagação, germinação e crescimento desta espécie nativa.

Com os dados obtidos após a instalação do experimento, a análise estatística foi realizada segundo o delineamento experimental inteiramente casualizado (DIC), com os tratamentos distribuídos em esquema fatorial $5 \times 3$ (substratos $\mathrm{x}$ profundidades), com os fatores mencionados acima, com um total de 15 tratamentos com sete repetições e 105 parcelas.

\section{Avaliação do desenvolvimento das mudas}

Os seguintes parâmetros foram avaliados: porcentagem de germinação, índice de velocidade de germinação, comprimento da parte aérea e raiz, diâmetro do coleto, números de folhas, massa seca total da parte aérea e da raiz e índice de qualidade de Dickson, que avalia a qualidade das mudas. Ao final do experimento foi retirado uma amostra total de $500 \mathrm{~kg}$ de cada um dos cinco substratos testados para análise de $\mathrm{pH}$, para que fosse verificada a influência deste na qualidade de mudas, e a disponibilidade de macronutrientes. Tal análise foi realizada no laboratório de fertilidade do solo na Universidade Federal do Acre

\section{Análise estatística dos dados}

Os dados foram submetidos ao teste da normalidade de distribuição dos erros e de homogeneidade da variância, e as médias comparadas pelo teste de Tukey, a nível de $5 \%$ de probabilidade. O programa estatístico utilizado na análise dos dados foi o Assistat versão 7.5. Os valores de porcentagem de germinação foram transformados em arc sen $(\mathrm{x} / 100)^{0,5}$ (BANZATTO; KRONKA, 2006). 


\section{Resultados e Discussão}

\section{Porcentagem de germinação}

Ao comparar as médias da porcentagem de germinação, por meio da análise de variância, entre substrato e profundidade verifica-se que existe pelo menos uma combinação ideal entre estes dois fatores que otimiza tal variável (Tabela 2). Estas interações mostram-se importantes, já que a capacidade de retenção de água e a quantidade de luz que o substrato permite chegar à semente podem ser responsáveis por diferentes respostas germinativas (FIGLIOLIA et al., 1993). Os substratos casca de castanha-do-brasil e terra de subsolo (S1) e casca de amendoim e terra de subsolo (S2) mostraram-se superiores em relação aos demais substratos quanto à característica avaliada quando a semeadura ocorreu a $0,0 \mathrm{~cm}$ de profundidade (superfície). Percebeu-se que a porcentagem de germinação decresceu à medida que a profundidade aumentou quase que unanimemente, exceto para o substrato terra de subsolo (S5) que se manteve constante, demonstrando não haver fotoblastismo positivo pelo último resultado.

TABELA 2: Porcentagem de germinação de mudas de Andira inermis subsp. inermis submetidas a diferentes substratos compostos por resíduos agroflorestais e profundidades, Rio Branco, Acre, 2009.

\begin{tabular}{cccc}
\hline \multirow{2}{*}{ Substrato } & \multicolumn{3}{c}{ Profundidade (cm) } \\
\cline { 2 - 4 } & $\mathbf{0 , 0}$ & $\mathbf{6 , 0}$ & $\mathbf{1 2 , 0}$ \\
\hline S1 ${ }^{1}$ & $100,00 \mathrm{aA}$ & $100,00 \mathrm{aA}$ & $71,43 \mathrm{bB}$ \\
S2 & $100,00 \mathrm{aA}$ & $28,57 \mathrm{~dB}$ & $28,57 \mathrm{~dB}$ \\
S3 & $85,71 \mathrm{bA}$ & $71,43 \mathrm{cB}$ & $57,14 \mathrm{cC}$ \\
S4 & $85,71 \mathrm{bA}$ & $85,71 \mathrm{bA}$ & $14,29 \mathrm{eB}$ \\
S5 & $85,71 \mathrm{bA}$ & $85,71 \mathrm{bA}$ & $85,71 \mathrm{aA}$ \\
\hline
\end{tabular}

Médias seguidas pela mesma letra minúscula na coluna e maiúscula na linha não diferem estatisticamente entre si, pelo teste de Tukey ao nível de $5 \%$ de probabilidade. ${ }^{1} \mathrm{~S} 1$ : casca de castanha-do-brasil triturada e terra de subsolo; S2: casca de amendoim triturada e terra de subsolo; S3: palha de arroz e terra de subsolo; S4: semente de açaí e terra de subsolo; S5: terra de subsolo (testemunha). Todos os tratamentos na proporção de $30 \%$ de resíduo agroflorestal e $70 \%$ de terra de subsolo, exceto S5 (testemunha) com 100\% de terra de subsolo.

\section{Î́ndice de velocidade de germinação}

Nas comparações entre as médias do índice de velocidade de germinação (IVG) das sementes submetidas a diferentes substratos compostos por resíduos agroflorestais e profundidades verificouse que os substratos casca de castanha-do-brasil e terra de subsolo (S1), casca de amendoim e terra de subsolo (S2) e semente de açaí e terra de subsolo (S4) proporcionaram uma maior rapidez na germinação das sementes de angelim-doce quando submetidos a $0,0 \mathrm{~cm}$ de profundidade (superfície). Isto é importante, pois uma maior velocidade de germinação traduz uma elevada uniformidade da germinação em um curto espaço de tempo, sendo esta uma característica desejável ao produzirem-se mudas (Tabela 3 ). A semeadura na profundidade de $6,0 \mathrm{~cm}$ também se mostrou adequada quando aliado ao substrato casca de castanha-do-brasil e terra de subsolo (S1), porém no dia-a-dia de um viveiro de mudas é menos oneroso semear à superfície $(0,0 \mathrm{~cm})$ que à $6,0 \mathrm{~cm}$ de profundidade, pois em profundidades menores pode-se dinamizar e aumentar a produção.

TABELA 3: Índice de velocidade de germinação de mudas de Andira inermis subsp. inermis submetidas a diferentes substratos compostos por resíduos agroflorestais e profundidades, Rio Branco, Acre, 2009.

\begin{tabular}{cccc}
\hline \multirow{2}{*}{ Substrato } & \multicolumn{3}{c}{ Profundidade (cm) } \\
\cline { 2 - 4 } & $\mathbf{0 , 0}$ & $\mathbf{6 , 0}$ & $\mathbf{1 2 , 0}$ \\
\hline S1 $^{1}$ & $0,04 \mathrm{aA}$ & $0,04 \mathrm{aA}$ & $0,02 \mathrm{aB}$ \\
S2 & $0,04 \mathrm{aA}$ & $0,01 \mathrm{~dB}$ & $0,01 \mathrm{bB}$ \\
S3 & $0,03 \mathrm{bA}$ & $0,02 \mathrm{cB}$ & $0,01 \mathrm{bC}$ \\
S4 & $0,04 \mathrm{aA}$ & $0,02 \mathrm{cB}$ & $0,005 \mathrm{cC}$ \\
S5 & $0,03 \mathrm{bA}$ & $0,03 \mathrm{bA}$ & $0,02 \mathrm{aB}$ \\
\hline
\end{tabular}

Médias seguidas pela mesma letra minúscula na coluna e maiúscula na linha não diferem estatisticamente entre si, pelo teste de Tukey ao nível de $5 \%$ de probabilidade. ${ }^{1} \mathrm{~S} 1$ : casca de castanha-do-brasil triturada e terra de subsolo; S2: casca de amendoim triturada e terra de subsolo; S3: palha de arroz e terra de subsolo; S4: semente de açaí e terra de subsolo; S5: terra de subsolo (testemunha). Todos os tratamentos na proporção de $30 \%$ de resíduo agroflorestal e $70 \%$ de terra de subsolo, exceto S5 (testemunha) com 100\% de terra de subsolo. 
Estes resultados concordam com os obtidos por Sousa et al. (2007) que estudando diferentes profundidades de semeadura na emergência e no desenvolvimento de plântulas de moringa (Moringa oleifera Lam.) verificou que houve redução dos valores do IVG, porcentagem de emergência e altura de plântulas a medida que se aumentava as profundidades de plantio.

$\mathrm{O}$ aumento da barreira física proporcionado pelas camadas mais profundas, em 6,0 e $12,0 \mathrm{~cm}$, foi, provavelmente, determinante para a redução da germinação das plântulas, índice de velocidade de germinação e altura das mudas (Tabela 4). As sementes ao germinarem absorvem água do solo e se expandem, assim, o crescimento do embrião deve ser suficiente para atingir a superfície do solo, onde encontrará luz suficiente para seu desenvolvimento normal (TILLMANN et al., 1994), caso o impedimento ocasionado pelo substrato ocorra haverá retardo no crescimento ou o mesmo não ocorrerá, ocasionando sua morte.

TABELA 4: Altura das mudas de Andira inermis subsp. inermis submetidas a diferentes substratos compostos por resíduos agroflorestais e profundidades, Rio Branco, Acre, 2009.

\begin{tabular}{cccc}
\hline \multirow{2}{*}{ Substrato } & \multicolumn{3}{c}{ Profundidade (cm) } \\
\cline { 2 - 4 } & $\mathbf{0 , 0}$ & $\mathbf{6 , 0}$ & $\mathbf{1 2 , 0}$ \\
\hline S1 ${ }^{1}$ & $34,24 \mathrm{dA}$ & $25,85 \mathrm{eB}$ & $25,00 \mathrm{cC}$ \\
S2 & $36,67 \mathrm{aA}$ & $27,00 \mathrm{~dB}$ & $26,10 \mathrm{bC}$ \\
S3 & $34,45 \mathrm{bA}$ & $33,02 \mathrm{aB}$ & $24,85 \mathrm{dC}$ \\
S4 & $34,38 \mathrm{cA}$ & $28,87 \mathrm{bB}$ & $24,00 \mathrm{eC}$ \\
S5 & $29,62 \mathrm{eA}$ & $28,02 \mathrm{cB}$ & $26,20 \mathrm{aC}$ \\
\hline
\end{tabular}

Médias seguidas pela mesma letra minúscula na coluna e maiúscula na linha não diferem estatisticamente entre si, pelo teste de Tukey ao nível de 5\% de probabilidade. ${ }^{1} \mathrm{~S} 1$ : casca de castanha-do-brasil triturada e terra de subsolo; S2: casca de amendoim triturada e terra de subsolo; S3: palha de arroz e terra de subsolo; S4: semente de açaí e terra de subsolo; S5: terra de subsolo (testemunha). Todos os tratamentos na proporção de $30 \%$ de resíduo agroflorestal e $70 \%$ de terra de subsolo, exceto S5 (testemunha) com 100\% de terra de subsolo.

\section{Altura das mudas}

O substrato casca de amendoim e terra de subsolo (S2) foi mais adequado para o incremento em altura das mudas (AM) quando a semeadura ocorreu na superfície, ou seja, a 0,0 cm de profundidade (Tabela 4). Resultados semelhantes foram observados para moringa (Moringa oleifera Lam.) (SOUSA et al., 2007), onde a maior altura de plântulas foi obtida na profundidade de semeadura de $2,0 \mathrm{~cm}$, ou seja, a mais próxima à superfície.

Esta característica, igualmente ao diâmetro do coleto (DC) e ao número de folhas (NF), deve ser observada com atenção, pois a AM se correlaciona positiva e significativamente com a biomassa e a área foliar (CLEMENT, 1995). Com isso, é possível criar alternativa de uso destas variáveis de crescimento para a seleção de plantas com elevado potencial produtivo ainda em viveiro (RODRIGUES et al., 2002).

\section{Número de folhas}

Em relação à característica número de folhas (NF), observou-se que a maioria dos substratos utilizados diferiu estatisticamente entre si, havendo uma variação quanto aos substratos testados e profundidades de semeadura. Resultados ótimos foram obtidos com o substrato semente de açaí e terra de subsolo (S4) quando as sementes de angelim-doce foram semeadas a $0,0 \mathrm{~cm}$ de profundidade (superfície). Também para casca de castanha-do-brasil triturada e terra de subsolo (S1), casca de amendoim triturada e terra de subsolo (S2), palha de arroz e terra de subsolo $(\mathrm{S} 3)$ à $6,0 \mathrm{~cm}$ de profundidade e casca de amendoim triturada e terra de subsolo (S2) à 12,0 cm de profundidade, houve um maior incremento em área foliar importante para uma maior e eficiente absorção de luz para a realização de fotossíntese (Tabela 5).

Embora não houve diferença na biometria das sementes de angelim-doce, a influência do tamanho da semente pode determinar esta característica, conforme Pereira et al. (2008). Porque as sementes de maior massa podem produzir mudas com a parte área mais desenvolvida e consequentemente maior número de folha (PEREIRA et al., 2008).

Melo (1999) estudando a formação de mudas do cafeeiro (Coffea arabica L.) em tubetes verificou que sementes maiores geraram mudas com maior número de pares de folhas e também maior área foliar, o que 
não traduz a diversidade de resultados obtidos neste experimento para tal variável.

TABELA 5: Número de folhas de mudas de Andira inermis subsp. inermis submetidas a diferentes substratos compostos por resíduos agroflorestais e profundidades, Rio Branco, Acre, 2009.

\begin{tabular}{cccc}
\hline \multirow{2}{*}{ Substrato } & \multicolumn{3}{c}{ Profundidade (cm) } \\
\cline { 2 - 4 } & $\mathbf{0 , 0}$ & $\mathbf{6 , 0}$ & $\mathbf{1 2 , 0}$ \\
\hline S1 & $4,75 \mathrm{dC}$ & $7,00 \mathrm{aA}$ & $5,75 \mathrm{cB}$ \\
S2 & $7,17 \mathrm{bB}$ & $7,00 \mathrm{aC}$ & $8,00 \mathrm{aA}$ \\
S3 & $6,00 \mathrm{cC}$ & $7,00 \mathrm{aA}$ & $6,50 \mathrm{bB}$ \\
S4 & $9,50 \mathrm{aA}$ & $6,17 \mathrm{cB}$ & $5,00 \mathrm{eC}$ \\
S5 & $6,00 \mathrm{cB}$ & $6,67 \mathrm{bA}$ & $5,40 \mathrm{dC}$ \\
\hline
\end{tabular}

Médias seguidas pela mesma letra minúscula na coluna e maiúscula na linha não diferem estatisticamente entre si, pelo teste de Tukey ao nível de $5 \%$ de probabilidade. ${ }^{1} \mathrm{~S} 1$ : casca de castanha-do-brasil triturada $\mathrm{r}$ terra de subsolo; S2: casca de amendoim triturada e terra de subsolo; S3: palha de arroz e terra de subsolo; S4: semente de açaí e terra de subsolo; S5: terra de subsolo (testemunha). Todos os tratamentos na proporção de $30 \%$ de resíduo agroflorestal e $70 \%$ de terra de subsolo, exceto S5 (testemunha) com $100 \%$ de terra de subsolo.

\section{Diâmetro do coleto}

Os ótimos resultados de diâmetro do colo (DC) e altura das mudas (AM) para o substrato casca de amendoim triturada e terra de subsolo (S2) a $0,0 \mathrm{~cm}$ de profundidade (Tabela 4 e 6) são corroborados por Lima et al. (2006), que estudando diferentes substratos (solo, esterco bovino, casca de amendoim, mucilagem de sisal, bagaço de cana e cama de frango) para produção de mudas de mamoneira (Ricinus communis L.) observaram que o composto formulado com casca de amendoim propiciou o melhor crescimento em altura e diâmetro do colo às mudas. Este resultado pode ser explicado através de análise química feita dos substratos avaliados, onde constataram a presença, considerável, de elevados teores de nitrogênio, fósforo e potássio.

O diâmetro do colo ou coleto aliado ao parâmetro altura de mudas pode ser um ótimo indicador de qualidade de mudas em viveiro, logo que para à avaliação desta característica ao longo do tempo não se faz necessário a morte das mudas, ou seja, é um método não destrutivo.
TABELA 6: Diâmetro do colo de mudas de Andira inermis subsp. inermis submetidas a diferentes substratos compostos por resíduos agroflorestais e profundidades, Rio Branco, Acre, 2009.

\begin{tabular}{cccc}
\hline \multirow{2}{*}{ Substrato } & \multicolumn{3}{c}{ Profundidade (cm) } \\
\cline { 2 - 4 } & $\mathbf{0 , 0}$ & $\mathbf{6 , 0}$ & $\mathbf{1 2 , 0}$ \\
\hline S1 $^{1}$ & $5,854 \mathrm{dA}$ & $4,854 \mathrm{Bb}$ & $4,218 \mathrm{aC}$ \\
$\mathrm{S} 2$ & $7,084 \mathrm{aA}$ & $4,535 \mathrm{cB}$ & $4,102 \mathrm{dC}$ \\
$\mathrm{S} 3$ & $6,296 \mathrm{cA}$ & $4,930 \mathrm{aB}$ & $4,125 \mathrm{cC}$ \\
S4 & $6,738 \mathrm{bA}$ & $4,453 \mathrm{~dB}$ & $4,000 \mathrm{eC}$ \\
S5 & $5,820 \mathrm{eA}$ & $4,450 \mathrm{eB}$ & $4,140 \mathrm{bC}$ \\
\hline
\end{tabular}

Médias seguidas pela mesma letra minúscula na coluna e maiúscula na linha não diferem estatisticamente entre si, pelo teste de Tukey ao nível de $5 \%$ de probabilidade. ${ }^{1} \mathrm{~S} 1$ : casca de castanha-do-brasil triturada e terra de subsolo; S2: casca de amendoim triturada e terra de subsolo; S3: palha de arroz e terra de subsolo; S4: semente de açaí e terra de subsolo; S5: terra de subsolo (testemunha). Todos os tratamentos na proporção de $30 \%$ de resíduo agroflorestal e $70 \%$ de terra de subsolo, exceto S5 (testemunha) com $100 \%$ de terra de subsolo.

A análise dos dados mostra um decréscimo do diâmetro das mudas em relação à profundidade, ou seja, à medida que a profundidade de semeadura aumentou obteve-se valores de diâmetro mais baixos. Isto pode indicar e auxiliar o estabelecimento das melhores mudas em campo com o maior crescimento em diâmetro.

\section{Comprimento da raiz}

Para o comprimento da raiz (CR) os melhores resultados obtidos foram para o substrato casca de castanha-do-brasil e terra de subsolo (S1) e palha de arroz e terra de subsolo (S3), na profundidade de $0,0 \mathrm{~cm}$. $\mathrm{O}$ pior resultado foi verificado para substrato casca de amendoim e terra de subsolo (S2), na profundidade de $12,0 \mathrm{~cm}$, seguido do substrato casca de castanha-do-brasil e terra de subsolo (S1), na profundidade de $12,0 \mathrm{~cm}$ (Tabela 7).

Estes resultados refutam os obtidos por Brito (2010), que estudando o efeito de diferentes substratos na germinação de sementes de timbaúba (Enterolobium schomburgkii Benth) - Mimosoidae verificou que todos os substratos que continham palha de arroz demonstraram-se inferiores, conferindo os piores 
resultados para a característica comprimento da raiz das plântulas.

TABELA 7: Comprimento da raiz de mudas de Andira inermis subsp. inermis submetidas a diferentes substratos compostos por resíduos agroflorestais e profundidades, Rio Branco, Acre, 2009.

\begin{tabular}{cccc}
\hline \multirow{2}{*}{ Substrato } & \multicolumn{3}{c}{ Profundidade (cm) } \\
\cline { 2 - 4 } & $\mathbf{0 , 0}$ & $\mathbf{6 , 0}$ & $\mathbf{1 2 , 0}$ \\
\hline S1 ${ }^{1}$ & $31,40 \mathrm{aA}$ & $23,13 \mathrm{aB}$ & $13,13 \mathrm{dC}$ \\
$\mathrm{S} 2$ & $21,53 \mathrm{aD}$ & $17,20 \mathrm{~dB}$ & $10,90 \mathrm{eC}$ \\
$\mathrm{S} 3$ & $26,93 \mathrm{aB}$ & $15,67 \mathrm{eC}$ & $16,35 \mathrm{cB}$ \\
$\mathrm{S} 4$ & $21,73 \mathrm{cB}$ & $20,60 \mathrm{bC}$ & $25,00 \mathrm{aA}$ \\
$\mathrm{S} 5$ & $20,00 \mathrm{eA}$ & $19,07 \mathrm{cB}$ & $17,46 \mathrm{bC}$ \\
\hline
\end{tabular}

Médias seguidas pela mesma letra minúscula na coluna e maiúscula na linha não diferem estatisticamente entre si, pelo teste de Tukey ao nível de $5 \%$ de probabilidade. ${ }^{1} \mathrm{~S} 1$ : casca de castanha-do-brasil triturada e terra de subsolo; S2: casca de amendoim triturada e terra de subsolo; S3: palha de arroz e terra de subsolo; S4: semente de açaí e terra de subsolo; S5: terra de subsolo (testemunha). Todos os tratamentos na proporção de $30 \%$ de resíduo agroflorestal e $70 \%$ de terra de subsolo, exceto S5 (testemunha) com 100\% de terra de subsolo.

\section{Massa seca da parte aérea e raiz}

Quanto à massa seca da parte aérea (MSPA), verificou-se que o substrato semente de açaí e terra de subsolo (S4), na profundidade $0,0 \mathrm{~cm}$ apresentou o melhor resultado, seguido do substrato casca de amendoim e terra de subsolo (S2) à $0,0 \mathrm{~cm}$ como pode ser observado na Tabela 8 , discordando com os resultados de Dumont (2009) que estudando o efeito de diferentes substratos na germinação de sementes de cedro rosa (Cedrela odorata L.), verificou que o substrato palha de arroz obteve resultado superior em relação aos demais para MSPA.

Marques et al. (1999) obtiveram o mesmo resultado testando o substrato palha de arroz na germinação de sementes de pau rosa (Aniba rosaeodora Ducke). Por outro lado, ao avaliar as diferentes profundidades observou-se que a massa seca da parte aérea teve relação substancial com a profundidade de plantio, logo que houve uma tendência a redução dos valores desta variável à medida que se aumentaram as profundidades de plantio (Tabela 8).

TABELA 8: Massa seca da parte aérea de mudas de Andira inermis subsp. inermis submetidas a diferentes substratos compostos por resíduos agroflorestais e profundidades, Rio Branco, Acre, 2009.

\begin{tabular}{cccc}
\hline \multirow{2}{*}{ Substrato } & \multicolumn{3}{c}{ Profundidade (cm) } \\
\cline { 2 - 4 } & $\mathbf{0 , 0}$ & $\mathbf{6 , 0}$ & $\mathbf{1 2 , 0}$ \\
\hline S1 ${ }^{1}$ & $3,704 \mathrm{eC}$ & $4,602 \mathrm{bB}$ & $4,617 \mathrm{bA}$ \\
S2 & $6,675 \mathrm{bA}$ & $2,862 \mathrm{dC}$ & $5,630 \mathrm{aB}$ \\
S3 & $5,104 \mathrm{cA}$ & $5,197 \mathrm{aA}$ & $4,692 \mathrm{bB}$ \\
S4 & $7,228 \mathrm{aA}$ & $3,361 \mathrm{cB}$ & $1,158 \mathrm{dC}$ \\
S5 & $4,174 \mathrm{Da}$ & $4,010 \mathrm{bA}$ & $4,067 \mathrm{cA}$ \\
\hline
\end{tabular}

Médias seguidas pela mesma letra minúscula na coluna e maiúscula na linha não diferem estatisticamente entre si, pelo teste de Tukey ao nível de 5\% de probabilidade. ${ }^{1} \mathrm{~S} 1$ : casca de castanha-do-brasil triturada e terra de subsolo; S2: casca de amendoim triturada e terra de subsolo; S3: palha de arroz e terra de subsolo; S4: semente de açaí e terra de subsolo; S5: terra de subsolo (testemunha). Todos os tratamentos na proporção de $30 \%$ de resíduo agroflorestal e $70 \%$ de terra de subsolo, exceto S5 (testemunha) com 100\% de terra de subsolo.

O substrato semente de açaí e terra de subsolo (S4) onde a semeadura ocorreu na profundidade de $0,0 \mathrm{~cm}$ (superfície) obteve o melhor resultado $(1,762 \mathrm{~g})$ para o acúmulo de biomassa da matéria seca da raiz (MSR) (Tabela 9). O substrato palha de arroz e terra de subsolo (S3) aparece com o pior resultado para esta característica avaliada à profundidade de $12,0 \mathrm{~cm}$ $(0,404 \mathrm{~g})$, concordando com os estudos de Brito (2010) para este resíduo, não sendo indicada a sua utilização quando se deseja obter esta característica. 
TABELA 9: Massa seca da raiz de mudas de Andira inermis subsp. inermis submetidas a diferentes substratos compostos por resíduos agroflorestais e profundidades, Rio Branco, Acre, 2009.

\begin{tabular}{cccc}
\hline \multirow{2}{*}{ Substrato } & \multicolumn{3}{c}{ Profundidade (cm) } \\
\cline { 2 - 4 } & $\mathbf{0 , 0}$ & $\mathbf{6 , 0}$ & $\mathbf{1 2 , 0}$ \\
\hline $\mathrm{S} 1^{1}$ & $1,314 \mathrm{dA}$ & $0,996 \mathrm{aB}$ & $0,715 \mathrm{bC}$ \\
$\mathrm{S} 2$ & $1,739 \mathrm{bA}$ & $0,571 \mathrm{eC}$ & $0,933 \mathrm{aB}$ \\
$\mathrm{S} 3$ & $1,467 \mathrm{cA}$ & $0,975 \mathrm{bB}$ & $0,404 \mathrm{eC}$ \\
$\mathrm{S} 4$ & $1,762 \mathrm{aA}$ & $0,585 \mathrm{~dB}$ & $0,542 \mathrm{cC}$ \\
$\mathrm{S} 5$ & $1,192 \mathrm{eA}$ & $0,849 \mathrm{Cb}$ & $0,466 \mathrm{dC}$ \\
\hline
\end{tabular}

Médias seguidas pela mesma letra minúscula na coluna e maiúscula na linha não diferem estatisticamente entre si, pelo teste de Tukey ao nível de $5 \%$ de probabilidade. ${ }^{1} \mathrm{~S} 1$ : casca de castanha-do-brasil triturada e terra de subsolo; S2: casca de amendoim triturada e terra de subsolo; S3: palha de arroz e terra de subsolo; S4: semente de açaí e terra de subsolo; S5: terra de subsolo (testemunha). Todos os tratamentos na proporção de 30\% de resíduo agroflorestal e 70\% de terra de subsolo, exceto S5 (testemunha) com 100\% de terra de subsolo.

\section{Índice de qualidade das mudas}

O padrão de qualidade das mudas estabelecido pelo índice de qualidade de Dickson (IQD) indica que as mudas cultivadas nas maiores profundidades $(6,0 \mathrm{e}$ $12,0 \mathrm{~cm})$ obtiveram menor qualidade independente do substrato utilizado, indicando que a profundidade é um fator que afeta diretamente a qualidade das mudas e consequentemente seu futuro estabelecimento em campo (Tabela 10).

TABELA 10: Índice de qualidade de Dickson de mudas de Andira inermis subsp. inermis submetidas a diferentes substratos compostos por resíduos agroflorestais e profundidades, Rio Branco, Acre, 2009.

\begin{tabular}{cccc}
\hline \multirow{2}{*}{ Substrato } & \multicolumn{3}{c}{ Profundidade $(\mathbf{c m})$} \\
\cline { 2 - 4 } & $\mathbf{0 , 0}$ & $\mathbf{6 , 0}$ & $\mathbf{1 2 , 0}$ \\
\hline $\mathrm{S} 1^{1}$ & 0,58 & 0,51 & 0,43 \\
$\mathrm{~S} 2$ & 0,93 & 0,31 & 0,53 \\
$\mathrm{~S} 3$ & 0,73 & 0,51 & 0,29 \\
$\mathrm{~S} 4$ & 0,98 & 0,32 & 0,21 \\
$\mathrm{~S} 5$ & 0,62 & 0,44 & 0,30 \\
\hline
\end{tabular}

${ }^{1} \mathrm{~S} 1$ : casca de castanha-do-brasil triturada e terra de subsolo; S2: casca de amendoim triturada e terra de subsolo; S3: palha de arroz e terra de subsolo; S4: semente de açaí e terra de subsolo; S5: terra de subsolo (testemunha). Todos os tratamentos na proporção de $30 \%$ de resíduo agroflorestal e $70 \%$ de terra de subsolo, exceto S5 (testemunha) com $100 \%$ de terra de subsolo.
As melhores mudas foram obtidas à profundidade de $0,0 \mathrm{~cm}(\mathrm{P} 1)$, destacando-se os substratos semente de açaí e terra de subsolo (S4) e casca de amendoim e terra de subsolo (S2) com as melhores médias $(0,93$ e 0,98$)$, respectivamente.

Este índice tem sido amplamente utilizado (ROSA et al., 2009), pois os parâmetros morfológicos utilizados no cálculo como altura total e diâmetro do coleto são fáceis de mensurar. Por ser um método destrutivo que utiliza dados de massa seca total (massa seca da parte aérea e massa seca da raiz) as mudas são mortas para a obtenção das variáveis, no entanto, outro método que pode ser utilizado sem nenhum receio é a razão entre as características altura de mudas e diâmetro do coleto. Porque são variáveis fáceis de mensurar ao longo do tempo não sendo necessária a eliminação das mudas, já que o objetivo de um viveiro é a comercialização das mesmas.

Parâmetros visuais também podem ser utilizados para verificar a qualidade de mudas, aliado a suas características morfológicas, como por exemplo, raízes de coloração clara, sistema radicular bem desenvolvido, caule sem tortuosidades e galhos sem bifurcação garantindo o sucesso posterior das mudas (DASSIE, 1995).

Ao relacionar o $\mathrm{pH}$ do substrato com o índice de qualidade das mudas verifica-se que os substratos com $\mathrm{pH}$ mais próximo a neutralidade proporcionaram a obtenção de mudas mais vigorosas, no caso o substrato contento semente de açaí $(\mathrm{pH}=5,1)$ e o substrato contendo casca de amendoim ( $\mathrm{pH}=4,5)$, o que já era esperado, pois as espécies das classes ecológicas denominadas secundárias e clímax são bem mais exigentes nutricionalmente do que as pioneiras (Tabela 11).

Ao final do experimento observou-se que a maior porcentagem de germinação, índice de velocidade de germinação e altura de mudas apresentaram uma tendência para profundidade de $0,0 \mathrm{~cm}$, ou seja, na superfície, o que permite inferir que esta é a profundidade mais adequada e indicada para a semeadura de angelimdoce (Tabelas 1, 2 e 4) . 
TABELA 11: Resultado da análise dos substratos compostos por resíduos agroflorestais, Laboratório de Fertilidade do Solo, UFAC, Rio Branco, Acre, 2009.

\begin{tabular}{|c|c|c|c|c|c|c|}
\hline Resultados analíticos & $S 1^{1}$ & S2 & S3 & S4 & S5 & $\mathrm{S}^{1}{ }^{1}$ \\
\hline pH (água 1:2,5) & 3,2 & 4,5 & 4,4 & 5,1 & 4,4 & 3,2 \\
\hline $\mathrm{Ca}+\mathrm{Mg}\left(\mathrm{cmol}_{\mathrm{c}} / \mathrm{dm}^{3}\right)$ & 3,75 & 2 & 1,75 & 2 & 2,6 & 3,75 \\
\hline $\mathrm{Ca}\left(\mathrm{cmol}_{\mathrm{c}} / \mathrm{dm}^{3}\right)$ & 2,3 & 1,4 & 1,4 & 1,2 & 1,75 & 2,3 \\
\hline $\mathrm{K}\left(\mathrm{mg} / \mathrm{dm}^{3}\right)$ & 225 & 396 & 220 & 506 & 53 & 225 \\
\hline $\mathrm{Na}\left(\mathrm{mg} / \mathrm{dm}^{3}\right)$ & 33 & 30 & 21 & 22 & 6 & 33 \\
\hline $\mathrm{K}\left(\mathrm{cmol}_{\mathrm{c}} / \mathrm{dm}^{3}\right)$ & 0,58 & 1,02 & 0,56 & 1,3 & 0,14 & 0,58 \\
\hline $\mathrm{Na}\left(\mathrm{cmol}_{\mathrm{c}} / \mathrm{dm}^{3}\right)$ & 0,14 & 0,13 & 0,09 & 0,1 & 0,03 & 0,14 \\
\hline $\mathrm{Mg}\left(\mathrm{cmol}_{\mathrm{c}} / \mathrm{dm}^{3}\right)$ & 1,45 & 0,6 & 0,35 & 0,8 & 0,85 & 1,45 \\
\hline $\mathrm{Al}\left(\mathrm{cmol}_{\mathrm{c}} / \mathrm{dm}^{3}\right)$ & 2,5 & 0,1 & 0,15 & 0,05 & 0,8 & 2,5 \\
\hline $\mathrm{Al}+\mathrm{H}\left(\mathrm{cmol}_{\mathrm{c}} / \mathrm{dm}^{3}\right)$ & 25,18 & 3 & 3,43 & 2,45 & 3,92 & 25,18 \\
\hline $\mathrm{C}(\mathrm{g} / \mathrm{kg})$ & 66,2 & 21,03 & 16,36 & 14,8 & 11,3 & 66,2 \\
\hline M.O. (g/kg) & 113,86 & 36,17 & 28,14 & 25,46 & 19,44 & 113,86 \\
\hline $\mathrm{P}\left(\mathrm{mg} / \mathrm{dm}^{3}\right)$ & 24 & 17 & 18 & 33 & 9 & 24 \\
\hline S. de Bases $\left(\mathrm{cmol}_{\mathrm{c}} / \mathrm{dm}^{3}\right)$ & 4,47 & 3,15 & 2,41 & 3,39 & 2,76 & 4,47 \\
\hline $\mathrm{CTC}\left(\mathrm{cmol}_{\mathrm{c}} / \mathrm{dm}^{3}\right)$ & 29,65 & 6,15 & 5,84 & 5,84 & 6,68 & 29,65 \\
\hline Valor V (\%) & 15 & 51 & 41 & 58 & 41 & 15 \\
\hline Sat. Al (\%) & 36 & 3 & 6 & 1 & 22 & 36 \\
\hline
\end{tabular}

${ }^{1} \mathrm{~S} 1$ : casca de castanha-do-brasil triturada e terra de subsolo; S2: casca de amendoim triturada e terra de subsolo; S3: palha de arroz e terra de subsolo; S4: semente de açaí e terra de subsolo; S5: terra de subsolo (testemunha). Todos os tratamentos na proporção de $30 \%$ de resíduo agroflorestal e $70 \%$ de terra de subsolo, exceto S5 (testemunha) com 100\% de terra de subsolo.

A partir deste estudo, foi possível concluir que a espécie apresentou comportamento diferenciado em relação aos substratos e profundidades avaliados. Os resíduos de semente de açaí, casca castanha-do-brasil e casca de amendoim mostraram-se promissores para obtenção de mudas mais vigorosas e de alta qualidade. Além disso, profundidades de semeadura excessivas para esta espécie prejudicam a germinação e o posterior desenvolvimento de mudas.

\section{Referências}

BANZATTO, D. A.; KRONKA, S. do N. Experimentação agrícola. 4 ed. Jaboticabal: FUNEP, 2006. 237 p.

BEZERRA, F. C.; FERREIRA F. V. M.; SILVA T. da C. Produção de mudas de berinjela em substratos à base de resíduos orgânicos e irrigadas com água ou solução nutritiva. Horticultura Brasileira, Fortaleza, v. 27, n. 2, p. S1348-S1352, 2009.
BRITO, D. de S. Efeito de diferentes substratos na germinação e vigor de sementes de timbaúba (Enterolobium schomburgkii Benth) - Mimosoidae. 2009. 43 f. Monografia (Graduação em Engenharia Florestal) - Centro de Ciências Biológicas e da Natureza, Universidade Federal do Acre, Rio Branco. 2010

CLEMENT, C. R. Growth and genetic analysis of pejibaye (Bactris gasipaes Kunth). Hawaii: University Hawaii, 1995. 221 p.

DASSIE, C. O berço das florestas. Silvicultura, São Paulo, v. 16, n. 64, p. 24-30, 1995.

DEICHMANN, V. Noções sobre sementes e viveiros florestais. Curitiba: UFPR - Escola de Florestas, 1967. 196 p.

DUMONT, M. L. Efeito de diferentes substratos na germinação de sementes de cedro rosa - Cedrela odorata L. (Meliaceae) em casa de vegetação. 2009. 40 f. Monografia (Graduação em Engenharia Florestal) - Centro de Ciências Biológicas e da Natureza, Universidade Federal do Acre, Rio Branco. 2009.

FERREIRA, R. B.; OLIVEIRA JÚNIOR, J. P. de; NAVES, R. V.; SALGADO, A. L. Desenvolvimento de mudas de Annona crassiflora Mart. (Araticum) em substratos com cinza de bagaço de cana. Pesquisa Agropecuária Tropical, Goiânia, v. 39, n. 1, p. 18-24, 2009. 
FIGLIOLIA, M. B.; OLIVEIRA, E. de C.; PINÃ-RODRIGUES, F. C .M. Análise de sementes In: AGUIAR, I. B. de; PIÑARODRIGUES, F. C. M.; FIGLIOLIA, M. B. (Ed.). Sementes florestais tropicais. Brasília: ABRATES, 1993. p. 137-174.

GOMES, J. M.; SILVA, A. R. Os substratos e sua influência na qualidade de mudas. In: BARBOSA, J. G.; MARTINEZ, H. E. P.; PEDROSA, M. W.; SEDIYAMA, M. A. N. (Ed.). Nutrição e adubação de plantas cultivadas em substratos. Viçosa: UFV, 2004. p. 190-225.

JELLER, H.; PEREZ, S. C. J. G. Efeito da salinidade de semeadura em diferentes profundidades na viabilidade e no vigor de Copaifera langsdorffi Desf. - Caesalpiniaceae. Revista Brasileira de Sementes, Brasilia, v. 19, n. 2, p. 219-225, 1997.

LEAO, J. R. A. Respostas de sementes e mudas de Angelim-doce Andira inermis (W. Wright) DC. subsp. inermis (Fabaceaepapilionoideae) a diferentes substratos e profundidades. 2011. 70 f. Monografia (Graduação em Engenharia Florestal) - Centro de Ciências Biológicas e da Natureza, Universidade Federal do Acre, Rio Branco. 2011.

LEÃO, J. R. A.; PAIVA, A. V. de. Utilização de resíduos agroflorestais como substrato no desenvolvimento de mudas de Andira inermis (W. Wright) DC. subsp. inermis. In: CONGRESSO INTERNACIONAL DE TECNOLOGIAS PARA O MEIO AMBIENTE, 2, 2010, Bento Gonçalves. Anais... Bento Gonçalves: FIEMA, 2010. 1 CD-ROM.

LIMA, R. de L. S. de; SEVERINO, L. S.; SILVA, M. I. de L.; JERÔNIMO, J. F.; VALE, L. S. do; BELTRÃO, N. E. de M. Substratos para produção de mudas de mamoneira compostos por misturas de cinco fontes de matéria orgânica. Ciência e Agrotecnologia, Lavras, v. 30, n. 3, p. 474-479, 2006.

MARQUES, A. da S. J.; VARELA, V. P.; MELO, Z. L. de O. Influência da cobertura e do sombreamento do canteiro na germinação de plântulas de pau rosa (Aniba rosaeodora). Acta amazônica, Manaus, v. 29, n. 2, p. 303-312, 1999.

MELO, B. Estudos sobre produção de mudas de cafeeiro (Coffea arabica L.) em tubetes: tipos de fertilização e diferentes substratos na produção de mudas de cafeeiro (Coffea arabica L.) em tubetes. 1999. 119 f. Tese (Doutorado em Fitotecnia) - Universidade Federal de Lavras, Lavras. 1999.

NEGREIROS, J. R. S.; ÁlVARES, V. S.; BRAGA, L. R.; BRUCKNER, C. H. Diferentes substratos na formação de mudas de maracujazeiro amarelo. Revista Ceres, Viçosa, v. 51, n. 1, p. 143-245, 2004.
PENNINGTON, R. T.; LIMA, H. C. Two new species of Andira from Bahia Brazil, and the influence of dispersal in determining their distributions. Kew Bulletin, Kew, v. 50, p. 557-566, 1995.

PEREIRA, P. C.; FREITAS, R. S.; MELO, B. de; FRANZÃO, A. A.; PEREIRA, A. P.; SANTANA, J. das G.; LUZ, J. M. Q.; MARTINS, M. Influência do tamanho de sementes na qualidade de mudas de tamarindeiro. Bioscience Journal, Uberlândia, v. 24, n. 4, p. 73-79, 2008.

PEREIRA, T. F. Efeito de diferentes substratos na germinação e vigor de sementes de ipê roxo - Tabebuia impetiginosa (Mart.) Standl. (Bignoniaceae). 2009. 38 f. Monografia (Graduação em Engenharia Florestal) - Centro de Ciências Biológicas e da Natureza, Universidade Federal do Acre, Rio Branco. 2009.

RODRIGUES, F. A.; CARVALHO, J. G. de; CURI, N.; PINTO, J. E. B. P.; GUIMARÃES, P. de T. G. G. Nutrição mineral de mudas de pupunheira sob diferentes níveis de salinidade. Pesquisa Agropecuária Brasileira, Brasília, v. 37, n. 11, p. 1613-1619, 2002.

ROSA, L. dos S.; VIEIRA, T. A.; SANTOS, D. S.; SILVA, L. C. B. da. Emergência, crescimento e padrão de qualidade de mudas de Schizolobium amazonicum Huber ex Ducke sob diferentes níveis de sombreamento e profundidades de semeadura. Revista de Ciências Agrárias, Belém, v. 52, p. 87-98, 2009.

SILVA JÚNIOR, A. A.; VISCONTI, A. Recipientes e substratos para a produção de mudas de tomate. Agropecuário Catarinense, Florianópolis v. 4, n. 4, p. 20-23, 1991.

SILVEIRA, M.; DALY, D. C. (Org.). Primeiro catálogo da flora do Acre, Brasil. Rio Branco: EDUFAC, 2009. 405 p.

SOUSA, A. H. de; RIBEIRO, M. C. C; MENDES, V. H. de C; MARACAJA, P. B; COSTA, D. M. Profundidades e posições de semeadura na emergência e no desenvolvimento de plântulas de moringa. Caatinga, Mossoró, v. 20, n. 4, p. 56-60, 2007.

TILLMANN, M. A. A.; PIANA, Z.; CAVARIANI, C.; MINAMI, K. Efeito da profundidade de semeadura na emergência de plântulas de tomate (Lycopersicon esculentum Mill.). Scientia Agricola, Piracicaba v. 51, n. 2, p. 260-263, 1994.

VASQUEZ-YANES, C.; OROZCO-SEGOVIA, A. Patterns of seed longevity and germination in the tropical rain forest. Annual Review of Ecology and Systematics, Brouwer, v. 24, n 1, p. 67-87, 1996. 